\title{
L'origen, la identitat $i$ el nom de la llengua catalana segons Constantí Llombart
}

\author{
[Origin, identity and name in Catalan language \\ according to Constantí Llombart]
}

\author{
Adrià MARTí-BADIA \\ Universitat de València \\ adria.marti@uv.es
}

\begin{abstract}
Resum: Al segle XIX se situa l'inici de la filologia romànica, i cada vegada més erudits cataloguen i estudien les diferents llengües romàniques i la llengua catalana en particular. Progressivament, en aquest període els erudits i escriptors de la catalanofonia realitzen afirmacions sobre el seu origen — compartit amb la llengua occitana o independent des de l'inici-, la seua identitat — subordinada a l'occità o autònoma com la resta de llengües romàniques- i el nom amb què cal referir-s'hi. Aquest treball analitza els coneixements de l'escriptor valencià Constantí Llombart (1848-1893) sobre l'origen, la identitat i el nom de la llengua catalana.
\end{abstract}

Paraules clau: Constantí Llombart, segle XIX, Origen, identitat i nom de la llengua catalana

ABstRACT: Romance philology emerged in the 19th century and more and more scholars started to categorise and study different Romance languages, the Catalan language among them. Progressively, during this period, Catalan-language writers and scholars made statements about its origin - either shared with Occitan language or independent from the beginning-, its identity — subordinated to Occitan or autonomous like other Romance languages - and the name given to the language. This paper analyses the knowledge of Valencian writer Constantí Llombart (1848-1893) about the origin, identity and name in Catalan language.

KeYWords: Constantí Llombart, 19th century, Origin, identity and name in Catalan language 


\section{Introducció}

La Renaixença, que va sorgir a la major part dels territoris de llengua catalana — sobretot a les grans ciutats com Barcelona, València i Palma-, va implicar un desvetlament de la consciència lingüística de molts catalanoparlants, sobretot d'aquells que van formar part dels cercles renaixentistes, bé com a protagonistes, o bé com a espectadors. Aquest augment de la consciència lingüística dels catalanoparlants, també va significar un increment en l'interés per la llengua pròpia i per les qüestions que l'envoltaven, com la seua història (interna i externa) i la creació literària, entre d'altres. En aquest sentit, cal destacar la formació de nous erudits, historiadors i filòlegs, que es van veure atrets per la lectura i l'estudi dels esdeveniments que configuraven la llengua i sobre la qual hi havia moltes preguntes que encara no havien trobat una resposta científica i contrastada.

Quin era l'origen de la llengua catalana? On i quan es va originar? Quina posició ocupava entre la resta de llengües romàniques? Era una llengua com ho eren el castellà, el francés, el portugués i l'italià? O era un dialecte? Si era un dialecte, de quina llengua ho era? De l'occità? Del castellà? Eren moltes interrogacions per respondre, a algunes de les quals s'hi havien aproximat anteriors erudits, historiadors i protofilòlegs nostrats.

Com afirma Bernat i Baltrons (2017: 315), els renaixentistes havien d'arribar a un mínim de consens sobre la llengua que volien restablir literàriament, i era una tasca difícil de materialitzar per la manca d'experts i de tradició en què recolzar-se després de segles de desatenció.

Paral-lelament, el naixement de la filologia romànica al segle XIX va esperonar nombrosos romanistes estrangers a conéixer la llengua catalana, els quals — amb el pas dels anys_ la van estudiar cada vegada amb més detall. Entre els objectius d'aquests filòlegs cal destacar la catalogació del català entre la resta de les llengües romàniques, així com la identitat, el nom i l'origen d'aquesta llengua. ${ }^{1}$

1 Per a les investigacions dels romanistes estrangers sobre l'origen, la identitat i el nom de la llengua catalana al segle xix i principis del xx, vegeu Martí-Badia (2019).

REVISTA VALENCIANA DE FILOLOGIA / IV (2020) p. I65-I88

ADRIÀ MARTÍ-BADIA

L'origen, la identitat $i$ el nom de la llengua catalana segons Constantí Llombart / I66 
Fruit d'aquest context, nombrosos erudits i escriptors catalanoparlants van poder conéixer els resultats de la romanística internacional, això sí, amb diferents posicionaments.

En definitiva, l'objectiu d'aquest treball és analitzar els coneixements de l'escriptor valencià Constantí Llombart (1848-1893)² sobre l'origen, la identitat i el nom de la llengua catalana a partir dels seus escrits que han arribat a l'actualitat, com llibres, discursos, articles i cartes.

\section{La identitat de la llengua catalana}

Constantí Llombart, pseudònim de Carmel Navarro i Llombart, va nàixer el 1848 en una família de pocs recursos del Cap i Casal. De formació autodidacta, va exercir els oficis d'escriptor, periodista i editor. D'ideologia progressista —republicana, més concretament—emprava el valencià com a llengua d'ús habitual.

Llombart reconeix el valencià com a part de la llengua catalana, com ho van fer la pràctica totalitat d'escriptors i erudits de la seua època. En aquest sentit té nombrosos precedents històrics, com Gaspar Escolano, Carles Ros, Lluís Galiana i Gregori Mayans, per citar alguns dels noms més coneguts.

El 1872 publica Niu d'abelles, ${ }^{3}$ al pròleg del qual es queixa que els valencians no s'interessen per la llengua pròpia:

Jo, lectors meus, em playnch en lo mig de l'ánima, quant algun rato considere lo llastimós abandono en que los vats d'el Túria han vingut á deixar la dolcísima llengua llemosina; aquella llengua sencilla ab la que, corrent lo segle XIII, lo rey En Jaume I d'Aragò mos va escriurer los magnifichs Furs y privilegis (1876a: VII).

2 Vegeu Estrela (2018) per a la vida i l'obra de Llombart.

3 Citem la segona edició, de 1876.

REVISTA VALENCIANA DE FILOLOGIA / iv (2020) p. I65-I88

ADRIÀ MARTÍ-BADIA

L'origen, la identitat i el nom de la llengua catalana segons Constantí Llombart / I67 
Una llengua que, segons Llombart:

[...] per motiu de lo casament de los reys católichs [...] no ha fet més qu'anar de mal en pitjor, fins al estrem de que tant los mallorquins, com los valencians y catalans, no fá molts anys, pera res la usaben en sos escrits. [...] Mes los catalans que son mes amants de les còses de sa tèrra, que nosaltres els valencians, [...] s'enrecordaren de la llengua materna, com se dia en lo segle xv, y proposaren á los seus germans los mallorquins y valencians, una crehuada literaria ab lo lloable fí de conquestar lo perdut tresor de la llengua llemosina (1876a: viII).

Més endavant, Llombart «la llengua catalana, qu'en lo fondo es la mateixa valenciana y mallorquina, ja que, com tots sabem, son totes les tres filles d'una mateixa mare qu'es la llemosina» (1876a: VIII-IX). Tot seguit es pregunta per què els valencians i mallorquins no han seguit l'empenta de Catalunya:

¿Qu'han fet los escriptors valencians y mallorquins? ¿En qué han atjudat á los seus germans de Catalunya, pera realiçar lo seu patriòtich pensament? En molt pòca còsa, en casi res.

Fòra d'unes quantes òbres dramátiques, pòques [...], y d'algunes composicions poètiques escrites en bòn llenguage llemosino-valenciá, lo demés, á mon mòdo de vorer, mes promte servix d'obstacle á la restauració de la llengua llemosina, que d'altra còsa.

Pero ¿quin podrá ser lo motiu que tenen los poetes valencians, pera no atjudar en esta empresa á sos germans de Catalunya? ¿Per qué no han d'escriurer, per lo menys, tant es [= en] la llengua llemosina com en la castellana, com ho fan los seus companys del Principat? (1876a: IX)

Dos anys després, al primer número de Lo Rat-Penat. Calendari Llemosí —aparegut el 1874- escriu l'article "Tot vól escomensar», en què afirma que aquesta publicació és «del mateix carácter» que Lo Gay Saber, editada a Barcelona. L’almanac valencià és:

REVISTA VALENCIANA DE FILOLOGIA / IV (2020) p. I65-I88

ADRIÀ MARTÍ-BADIA

L'origen, la identitat i el nom de la llengua catalana segons Constantí Llombart / I 68 
Un periódich literari llemosí [...] pera l'objecte d'anar responent d'alguna manera alslloablesesfórços [= als lloables esforços] d'els catalans en favor del renaiximent de les nostres lletres (1874: 9).

Unes «lletres» compartides amb balears i catalans que a Catalunya estan promovent moltes publicacions: «En Barcelona, lo moviment literari llemosí d'aquest any, ha donat llóch á que s'escrigueren y publicaren moltes y molts estimables produccions» (1874: 10), de les quals en dona compte. També esmenta la

Biblioteca catalana, que formada de les principals obres qu'en la nóstra llengua materna s'han escrit en lo Principat y en los antichs realmes de Mallorca y Valencia, publica En Marian Aguiló y Fuster, fent aixi no curt servici á les lletres de la térra (1874: 10-11).

A més, esmenta l'escriptor mallorquí Jeroni Rosselló, «acreedor á l'agrahiment de tots los que com nosaltres estimen la llengua llemosina» (1874: 11). Després és el moment de saber "qu'és lo qu'els literats y poetes de Valencia n'han fet en favor del moviment literari llemosí en aquests darrers mesos» (1874: 13). Entre aquesta informació afirma que «tenim bastant adelantat» l'Ensaig d'ortografía valenciana, "que tanta falta fa pera anarne unificant la llengua llemosina» (1874: 14). I, més endavant, recrimina directament a

l'Ateneo científich, literari y artístich de València, que tant podia atjudarne á restaurar la llengua d'els nóstres antecesors, ocupat en les cóses dels forasters, apenes si s’enrecórda de les de sa casa. ¿Qu'éls costaria á llurs il-lustrats individuos, consagrarne, de quant en quant, algunes de les seues sesions á les lletres llemosines? (1874: 15-16)

Anys després, la nit del 31 de juliol de 1878, se celebra la sessió inaugural de presentació de Lo Rat Penat —entitat de la qual Llombart és un dels principals impulsors-, en la qual llegeix el seu discurs Excel-lencies de la llengua Llemosina. En aquest, Llombart exclama:

REVISTA VALENCIANA DE FILOLOGIA / IV (2020) p. I65-I88

ADRIÀ MARTÍ-BADIA

L'origen, la identitat i el nom de la llengua catalana segons Constantí Llombart / I 69 
¡Ya, per fi, Valencia, la gentil ciutat de l’amor y la poesía, la perla del Túria, sembla correspondre al crit patriotich de renaiximent donat fa temps per nostres germans de Catalunya! ¡Ya al cap aplegà hora! (1878b: 9).

I a continuació exhorta el seu públic amb les paraules següents:

No, valencians, no es morta nostra expresiva llengua llemosina, com los seus malhavirats inimichs [= enemics] semblaba desijaben, gracies als generosos esforços de nostres germans de Catalunya y de les illes Malloques, esforços generosos que de hui en avant debem nosaltres ab tot fervor imitar (1878b: 11).

Altrament, també el 1878 publica a Lo Rat-Penat. Calendari Llemosí l'article inicial de la publicació, en el qual comença afirmant:

Profitosos, certámens han segut los dotce darrers mesos pera les lletres llemosines [...]. Tres ó quatre anys d'entusiasme [...] y haurém [...] lograt posarnos al nivell de nostres germans de Catalunya (1878c: 11).

$\mathrm{Al}$ seu parer, els valencians no tenen interés per la llengua pròpia perquè «tampòch lo públich de nòstra bella ciutat correspòn [...] á la lloable restauració de nòstres lletres llemosines, iniciada fa temps en Barcelona» (1878c: 12). I tot seguit ressenya les novetats editorials valencianes. Endemés, «en Barcelona no cal per qué dir qu'es seguix de fórt y ferm treballant per nòstra restauració literaria» (1878c: 12) i, com a prova, dona compte de les obres publicades darrerament.

Un any més tard publica la seua gran obra Los fills de la morta-viva, recull «bio-biobliográfich» dels autors valencians que escriuen en «llemosí». Aquesta comença amb un pròleg en què defensa la llengua pròpia, com s'observa quan parla del decret de Nova Planta (1707) i afirma que «tal fon la maléfica influencia que'l haberse abolit en estos antichs realmes los furs y privilegis eixerci en la nostra llemosina parla, imposta com oficial la de Castella» (1879a: $\mathrm{xxV})$. És a dir, el català —i els furs - foren abolits dels territoris de parla ca-

REVISTA VALENCIANA DE FILOLOGIA / IV (2020) p. I65-I 88

ADRIÀ MARTÍ-BADIA

L'origen, la identitat i el nom de la llengua catalana segons Constantí Llombart / I 70 
talana i això tingué unes conseqüències desastroses. Més endavant, esmenta nombrosos escriptors en català al País Valencià i afirma:

Tots ells il-lustrats escriptors ó distinguits poetes valencians, los quals notoriament estimulats del renaiximent lliterari llemosí portat estos darrers anys á efecte pels fills del Principat de Catalunya [...], segurament conseguiran tornar dins poc, com es desitja, a són natural explendor la llemosina parla (1879a: XXVI-XXVII).

També cal esmentar quan parla de Carles Ros i afirma que «mamprengué per sa propia iniciativa la dificultosa tasca de restablir en nostra terra l'idioma» (1879a: 30$),{ }^{4}$ per a explicar amb una nota a peu de pàgina:

No es, com alguns creuen, un real decret lo que á una llengua, li dona ó pot llevarli la categoria d'idioma, sino ses propies excelencies, [...] com aixís mateix lo mérits guanyats per ella ab los grans monuments lliteraris qu'ab son talent los seus escriptors y poetes saberen erigirli. ¡Cónstelos als que, sens coneiximent de causa, els incomoda lo nom d'idioma aplicat á la llengua llemosina, á la rica llengua dels seus ávis! (1879a: 30)

El mateix 1879 Llombart escriu l'article introductori de la revista Lo Rat-Penat. Calendari Llemosí, en el qual manifesta que «l'ensaig d'establir lo teatro lemosino-valenciá, pensament llastimosament frustrat per haber volgut los autors dramatich[s] valencians collir lo fruyt avans de mandurarse» (1879b: 11). Més endavant torna a lamentar el poc interés dels valencians:

¿Es qu'els valencians acás desdenyen, sens motiu, les coses de sa pátria? ¿Es que sa llengua, qu'es l'esperit del poble, no els mereix mes que despreci? Si, desgraciadament, aixina fora, paraules nos mancarien pera expresar l'afronte (1879b: 12).

4 La figura de Carles Ros és molt important per a Llombart, és la seua referència principal. De fet, hi ha molts paral-lelismes entre l'obra d'ambdós escriptors, encara que foren d'èpoques diferents.

REVISTA VALENCIANA DE FILOLOGIA / iv (2020) p. I65-I88

ADRIÀ MARTÍ-BADIA

L'origen, la identitat i el nom de la llengua catalana segons Constantí Llombart / I7 I 
A continuació repassa les publicacions i els certàmens d'arreu dels territoris de parla catalana, i conclou donant compte de «l'obra qu'en castellá escriu En F. M. Tubino, sobre lo renaiximent lliterari llemosí en Catalunya, les Balears y Valencia» (1879b: 16), en referència a l'obra Historia del Renacimiento literario contemporáneo en Cataluña, Baleares y Valencia (1880) de l'historiador Francisco M. Tubino.

Llombart és premiat als Jocs Florals de València de 1880 per la seua obra Ensayo de Ortografía lemosino-valenciana "con la Abeja de oro ofrecida á este tema por el Ateneo Científico, Literario y Artístico de Valencia» (1887a: Xv). Treball que restà inèdit fins la reedició del Diccionario valenciano-castellano de Josep Escrig (1887) i que «ex profesamente lo ha traducido su autor [...] del lemosín en que fué escrito para dicho Certamen, al castellano en que ahora se publica» (1887a: Xv). ${ }^{5}$ Llombart proposa que la millor solució per a la llengua és

Establecer una doble división de lugar y tiempo en nuestra lengua [...]. La primera de ellas [...] la que al punto donde se habla se refiere, reducida está á la aplicación indistinta del calificativo lemosín á las tres diversas ramas del árbol de nuestra lengua, que son el catalán, el mallorquín y el valenciano, denominándose respectivamente lemosino-catalán, lemosino-mallorquín y lemosino-valenciano, según a la región á que corresponda; y no omitiéndose nunca el dictado lemosín, ya que tal fué el nombre de pila que, por razón de haber nacido en Limoges, así como por haber nacido en Castilla se denomina la lengua española castellana, la es en todos casos apropiado. De este modo obtendrianse las consiguientes ventajas de facilitar en mucho la unificación de nuestra lengua, pudiendo, por otra parte, desarrollarse autonómicamente en cada una de por sí, evitándose quizás mezquinos recelos ó antagonismos que entre sus cultivadores pudieran algún día suscitarse.

Respecto á la división de tiempo, bueno fuera atenerse al pasado, al presente y aun al porvenir, y establecer tres diferentes géneros de lenguaje: uno correspondiente al pasado, ó sea el lemosín arcaico; otro al presente,

5 Vegeu Guardiola i Savall (2005) per a l'aportació de Llombart al diccionari d'Escrig.

REVISTA VALENCIANA DE FILOLOGIA / IV (2020) p. I65-I 88

ADRIÀ MARTÍ-BADIA

L'origen, la identitat $i$ el nom de la llengua catalana segons Constantí Llombart / I72 
que podría llamarse lemosín literario, y ha de ser el que con el actual renacimiento se forme; y por último, el dialecto valenciano, especie de caló, corruptela de nuestra antigua lengua valenciana, y que hoy ordinariamente usamos (1887a: XVII).

Així, defensa la unitat de la llengua i alhora

Deixa oberta la porta al desenvolupament de cada variant, cosa que hem d'entendre més com un respecte per les peculiaritats regionals que com l'intent de formar models lingüístics separats (Climent 2003: 285).

El mateix 1887, Llombart publica Valencia antigua y moderna, ${ }^{6}$ en què dedica un apartat a «La lengua lemosino-valenciana» (1887b: 63-67), i on realitza també interessants afirmacions sobre la identitat de la llengua catalana. Pel que fa al País Valencià, sosté:

D. Guillem de Corberá, nombrado en 1216 ayo y mayordomo del infante D. Jaime I de Aragón, instruyó en ella á su augusto discípulo, que algunos años despues la introdujo en Valencia al tiempo de la conquista.

Nuestra lengua, hija como la catalana y mallorquina del provenzal, no es sustancialmente diferente más que en el dialecto, pronunciacion, conjunto de voces, vocablos árabes vulgares y romanos. Con el heredamiento y asiento que hicieron en nuestra capital los castellanos, navarros, portugueses, prohenzales, romanos, aragoneses y catalanes, agregáronse á la lengua de $\mathrm{O} c$ varias voces, con que se formó un nuevo dialecto ó romance provincial, segun lo declaró el mismo rey Conquistador (1887b: 63-64).

Aleshores, «el agregado de tantas lenguas formó un tercer idioma, conocido antiguamente en nuestro reino por lengua materna» (Llombart 1887b:

6 Obra que guarda un gran paral-lelisme amb la que va escriure Marc Antoni d'Orellana a finals del segle xviII; no només en el títol, sinó també en el contingut. Vegeu Martí-Badia (2013) per a la ideologia lingüística d'Orellana.

REVISTA VALENCIANA DE FILOLOGIA / IV (2020) p. I65-I 88

ADRIÀ MARTÍ-BADIA

L'origen, la identitat i el nom de la llengua catalana segons Constantí Llombart / I73 
64). Definició que, a més d'errònia, Llombart la copia amb exactitud de la Historia de la ciudad y reino de Valencia de Vicent Boix (1845: 491) sense citar-lo. L'explicació llombartiana finalitza en el temps present, quan afirma

En nuestros dias habia llegado la lengua lemosina á tal extremo de decadencia, que apenas si algunas personas eruditas la entendian; empero gracias á algunos buenos patricios amantes de las glorias de su pais, con cuya cooperacion fundamos la Sociedad denominada Lo Rat-Penat, que tiene por principal objeto despertar el cariño de los valencianos á su olvidada lengua materna, lo cual nos hace creer que todavía alcanzará su antiguo esplendor el lemosin, y veremos reflorecer esta pomposa rama de la literatura nacional (1887b: 66-67).

D'altra banda, Llombart va projectar per al gener de 1888 un congrés filològic a València al qual assistirien valencians, catalans i balears (Marcet 1991: 126). L'Arch de Sant Martí informava, en un article anònim, que es tractava d'un congrés «filológich-llemosí», en el qual

Se posará á discussió lo següent cuestionari.

Primer. Unificació de la llengua que avuy se parla en Catalunya, Valencia y Balears, sa conveniencia, oportunitat y bases fonamentals.

Segon. Calificació y nom de dita llengua.

Tercer. Aptitut de la mateixa pera'l cultiu de tots los géneros literaris examen dels que han obtingut menos cultiu y medis pera fomentarlo.

Cuart. Designació d'autors clássichs.

Quint. Concessions que convindria impetrar del poder públich en favo[r] del llemosí, ab relació al llenguatje oficial y á la ensenyansa (Anònim 1887: 949-950).

Tanmateix, el congrés no s'arriba a realitzar perquè fou boicotejat, segons Marcet (1991: 126), pel sector conservador de la Renaixença valenciana.

Pel que fa a les relacions epistolars, el 3 de gener del 1888, Llombart envia una carta a Verdaguer, en la qual li confessa:

REVISTA VALENCIANA DE FILOLOGIA / IV (2020) p. I65-I 88

ADRIÀ MARTÍ-BADIA

L'origen, la identitat $i$ el nom de la llengua catalana segons Constantí Llombart / I74 
Confie solament en que vos y algunes altres persones de tan profons [= profunds] coneixements en nostra llengua, se dignarán ilustrarme en moltissims dels punts en que ha de tropeçar ma insuficiència (Verdaguer 1981: 123).

En l'àmbit privat, doncs, torna a mostrar la seua consciència d'unitat lingüística quan empra el sintagma «nostra llengua» per a designar el conjunt de la llengua catalana.

\section{El nom de la llengua catalana}

Llombart és el valencià que més va defensar els termes «llemosí» i «llengua llemosina» per a referir-se al conjunt de la llengua catalana, com a estratègia per a evitar la denominació unitària «català» —i derivats— perquè no satisfà les seues aspiracions identitàries.

En l'article inicial del segon número de Lo Rat-Penat. Calendari Llemosí —aparegut el 1875- Llombart anuncia els projectes que «nos habem proposat» per a "portarne á cap lo renaiximent de les lletres llemosines», que són: en primer lloc, la creació de «L'Académia de lletres llemosines» amb el nom «Los fills de la Mórta viva»; en segon lloc, «una bona gramática llemosino-valenciana»; en tercer lloc, «una Ortografía»; en quart lloc, «lo perfeccionament de lo Diccionari de lo Sr. En Joseph Escrig»; en cinqué lloc, «un periódich»; en sisé lloc, «la "Biblioteca llemosina", compósta de les principals obres llemosines, antigues y modernes»; i, en seté lloc, la celebració dels «los Jochs florals» (1875: 13-14). Tanmateix, com indica Martí Mestre (2005: 203), aquests projectes només es van assolir en part, ja que el context social i polític era poc favorable i, a més, Llombart va rebre pocs suports.

Els escrits de Llombart van cridar l'atenció de l'escriptor català Antoni Careta i Vidal, que l'any 1875 publica l'article «Bons recorts» al Calendari Catalá del any 1876, en què interpel-la directament Llombart respecte al nom i la identitat de la llengua catalana. Segons Careta i Vidal:

REVISTA VALENCIANA DE FILOLOGIA / IV (2020) p. I65-I 88

ADRIÀ MARTÍ-BADIA

L'origen, la identitat $i$ el nom de la llengua catalana segons Constantí Llombart / I 75 
A Valencia per iniciativa d'En C. Llombart acaba de fundarse una societat ab lo títol de Los fills de la morta viva. Molt nos satisfan estas manifestacions que proban lo despertament de nostre esperit en aquella terra; pero en veritat nos mortifica sentir als valencians com parlant de sa llengua l'anomenan llemosina. ¿A qué obeeix tal innovació? ¿Será esperit de rebetlia á son origen? No'u podém creure des del moment que’ls veyem units ab los catalans y'ls mallorquins cantar en una mateixa llengua, que no es pas cert la castellana, la germandó del[s] tres pobles y las comunnas glorias de nostre passat; mes no será de mes encomenarlos que tingan mes amor al niu d'hont han eixit, que no'ns sembla del cas que'ls nets del primer poeta satírich se batejen ab lo nom de poetas llemosins, valentse per ferho de la lleng[u]a catalana, lleng[u]a parlada dels quins, deixant l'host del gran En Jaume, se quedaren á poblar y encristianir la Valencia mora.

Y no servesca aixó de pretest per dar lo nom absolut de valenciana á la lleng[u]a que á Valencia parlan; digas en hora bona valenciá, mallorquí, com á dialectes ó modificacions del idioma catalá, com se deya jónich, dórich, eólich, ó átich á quiscuna modificació del grech; mes no’s cerque madrastra qui tinga bona mare, que may un fill podrá llegitimar ab cap subterfugi l'acte mes lleig que per la naturalesa pot cometre, lo renegar del nom payral.

No's cerquen noms estranys quan existeix lo propi. Lleng[u]a llemosina no vol dir mes que la lleng[u]a parlada á Limoges (França) y que no es, ni [ha] estat, ni será may la lleng[u]a catalana que’s, para aquí y, mes ó menys adulterada, á Valencia y á Mallorca (1875: 9-10).

Unes paraules que, segons Antoni Ferrando (2006: 214), són la primera manifestació del complex de superioritat lingüística dels catalans respecte del valencià i del mallorquí. La rèplica de Llombart a Careta i Vidal arriba el mateix 1875 a les pàgines de Lo Rat-Penat. Calendari Llemosí, revista dirigida per ell mateix. En aquest article, Llombart afirma que Careta i Vidal «se queixa de qu'els valencians dónem á nostra llengua lo nóm de llemosina» (1875: 16):

REVISTA VALENCIANA DE FILOLOGIA / IV (2020) p. I65-I 88

ADRIÀ MARTÍ-BADIA

L'origen, la identitat $i$ el nom de la llengua catalana segons Constantí Llombart / I76 
Sense perjuhí de contestarli al Sr. Careta y Vidal mes estensament, ja qu'así no podem per falta de llóch, sóls li dirém, que pera no donar motiu á rivalitats entre los póbles que parlen nóstra llengua, sempre hem cregut lo mes convinent l'aplicació de lo calificatiu llemosina á les diferents rames que, despreses de l'antich árbre naixcut en la provençal Limoges, varen arrailar en Catalunya, Valencia y les illes Balears. Este es lo nóstre pensament, y nos pareix que res te de particular que, aixina com la llengua qu'es parla en tota Espanya s'anomena castellana, per qu'en Castella va naixer, la que parlem hui en la patria llemosina, com lo Sr. Balaguer l'anomena, ó siga Catalunya, Valencia y Mallorca, prenent lo nóm d'ahon tingué lo bressol, se denomine llemosina, á imitació de lo qu'els espanyols ham fet en la castellana.

¿Es asó, com diu lo Sr. Careta, esperit de rebetlia á son oritjen? ¿Es asó renegar del nom payral? De ninguna manera (1875: 16).

Aquestes «rivalitats» de Careta i Llombart, segons Joan Fuster (1962: 8), només incidien en el nom. Així, l'ascendència «provençal» de la llengua catalana és esmentada per Llombart només de passada, amb l'objectiu de justificar el mot «llemosí» (Rafanell 1991: 40-41). A més, com observa Rafanell (1991: 41), Llombart readapta la "pàtria llemosina» de Víctor Balaguer, excloent el «llemosí» de Provença i les zones adjacents —on ja estava liquidat—i pren com a objecte el «llemosí» viu i particular dels països catalans.

De fet, Llombart palesava el seu objectiu: «nos habem proposat portarne á cap lo renaiximent de les lletres llemosines» $\mathrm{i}$ «a aquest objecte, teniem pensat, si be pera mes abant, lo establir en Valencia un centre ahon se concentraren tots los disgregats elements literaris llemosins» (1875: 13). I a recer de l'explicació de l'esmentada acadèmia, enumera els projectes que pretén dur a terme per al «renaiximent de les lletres llemosines»:

Los fills de la Mórta viva, qu'este será lo nom que l'Académia de lletres llemosines ha de dur, podrá ab l'esforç de tots los aymadors de nóstres glories, eixecarne lo pendó de la nova creuhada dins lo punt qu'en lo

REVISTA VALENCIANA DE FILOLOGIA / IV (2020) p. I65-I 88

ADRIÀ MARTÍ-BADIA

L'origen, la identitat i el nom de la llengua catalana segons Constantí Llombart / I 77 
dia li correspón per dret ocuparne. D’ella, ab l'activa cooperació d'els intellijens [= intel·ligents], podrá ixirne una bona gramática llemosino-valenciana, que tan utilosa pot sernos; una Ortografía, millor que lo breu ensaig que tenim á punt de donar al públich; podriem també emprendrer lo perfeccionament de lo Diccionari de lo Sr. En Joseph Escrig, ${ }^{7}$ que tant podia millorarse; podriem anar estudiant les reformes hui compatibles en l'estat de la nostra llengua; podriem publicarne un periódich per lo promte, y tal volta, mes enllá, la «Biblioteca llemosina», compósta de les principals obres llemosines, antigues y modernes, que tenim grans desitjos de donar á la estampa. Altra de les cóses que podriem durne á cap per medi de l'Academia, serien los Jochs Florals, los quals celebraría ab tot l'aparament qu'en l'antigor sels donaba, y que tant han cridat l'atenció de tota Espanya, en los últims anys qu'en Barcelona es verifiquen.

Tot asó conseguiríem, probablement, lo dia que s'establirá l'Academia; y per a lo qual contant ab l'important cooperació d'els mes distinguits literats qu'escriuen en lo llenguatje de nostres antepasats, entr'ells, en primer lloch los eminents cronistes de Catalunya y Valencia, En Víctor Balaguer y En Vicent Boix respectivament, que nos la oferiren, estant preparantse los treballs preliminars (1875: 13-14).

Continua l'article afirmant que, per a la inauguració de l'esmentada Acadèmia, està escrivint el discurs inaugural intitulat «Excel-lencies de la llengua llemosina» i també informa que s'està redactant un projecte d'estatuts «que tindrem l'honor de sometrer á la discusió y aprobació de los senyors de la comisió que pera l'objecte nomene l'Academia» (1875: 14).

Un any després, també a les pàgines de Lo Rat-Penat. Calendari Llemosí, Llombart (1876b: 11) lamenta que «lo públich valenciá no ha correspòst encara ab lo gran interés y lo entusiasme que deguera despertar en éll nòstra causa gloriosa qu'es la sehua». I fa saber que ell mateix ha editat i publicat les Obres festives del religiós dominicà del set-cents Francesc Mulet (1876), tasca

7 Diccionari que va reeditar l'any $1887 \mathrm{amb}$ ampliacions seues. Vegeu Llombart (1887a).

REVISTA VALENCIANA DE FILOLOGIA / IV (2020) p. I65-I 88

ADRIÀ MARTÍ-BADIA

L'origen, la identitat i el nom de la llengua catalana segons Constantí Llombart / I 78 
que continuarà un any després amb Lo procés de les olives de Bernat Fenollar (et al.), obra - aquesta darrera-que esdevé el primer exemplar de la col·lecció Biblioteca Valentina que ell mateix impulsa, tal com ja havia avançat el 1875 a les pàgines de Lo Rat-Penat. Calendari Llemosí. A continuació prossegueix en la defensa de la llengua pròpia, carrega contra els valencians «fills rebordonits» i dona compte de les produccions dels autors valencians, entre les quals es troba Rimas de Vicent V. Querol (1877), que anomena «catalanes» les tres poesies «llemosines» que conté el llibre, fet que no entén i per això li ho critica:

Lo que sí que no ham pogut compendrer, y debem dirho, es lo motiu per qué lo poeta, tan amant sempre de Valencia, ha tingut l'estrany capritjo de titolarne Rimas catalanas les tres úniques poesíes llemosines qu'estam$\mathrm{pa}, \tan$ notables com tot lo eixit de sa ploma, sent aixina qu'en llemosina llengua están escrites.

¿Per quína rahó, que nosaltres, Sr. Querol; no hi acertem á explicarnos, denominarles catalanes y no llemosines? No ho entenem, Sr. Querol, no ho entenem (1877: 13).

Tot seguit, destaca la publicació de les Tragèdies de Víctor Balaguer (1876), que «á cridat l'atenció, no sols de la terra llemosina, sino també de tota Espanya» (1876b: 15). És a dir, fa referència als territoris de parla catalana amb el sintagma «terra llemosina». El mateix any, Llombart edita l'obra col-lectiva Lo procés de les olives (1877), en què fa el següent comentari al conegut proemi d'Onofre Almudèver:

Així discretament parlant s'expressava, més de tres-cents anys enrere (1561), lo poeta valencià, Onofre Almudèver, tan digne de lloança [...], per a estimular al conreu i cultiu de la llemosina llengua. ${ }^{8}$

8 Text que citem de Pitarch (1972: 138), que el transcriu i l'adapta a l'ortografia actual.

REVISTA VALENCIANA DE FILOLOGIA / IV (2020) p. I65-I 88

ADRIÀ MARTÍ-BADIA

L'origen, la identitat i el nom de la llengua catalana segons Constantí Llombart / I 79 
El 1878 imprimeix Abelles y abellerols, encapçalada per l'escrit intitulat «Cuatre mots sobre epigrames» (1878a: VII-XII), en què defensa la llengua pròpia de manera contundent i afirma que «en colaborasió en atres varios poetes valensians, mallorquins y catalans, vaig donar á llum el primer epigramari escrit en la nostra llengua» (1878a: VIII), en referència a Niu d'abelles (1872). I, més endavant, es refereix a la «llengua valensiana» (1878a: IX), en al·lusió a la llengua del poble valencià.

D'altra banda, en l'esmentat discurs Excel-lencies de la llengua Llemosina del 31 de juliol de 1878, Llombart precisa respecte al nom de la llengua:

Aquella mateixa noble llengua llemosina, apellada á les hores [en el passat] del pais ó valenciana, que nostres majors usaren desde la gloriosa conquesta d'aques[t] regne. Aquesta llengua, que apellarém nosaltres llemosina (1878b: 12).

Una altra mostra del seu llemosinisme onomàstic el trobem en Los fills de la morta-viva, una obra plena d'expressions i noms per a designar la llengua catalana, com «renaiximent lliterari llemosí» (1879a: XXvi), «llemosina parla» (1879a: XXVII), "composicions llemosines»(1879a: 398), "llemosino-valenciá» (1879a: 761); en la qual també troba l'ocasió per a tornar a criticar el títol de les Rimes catalanes de Querol, malgrat que aquest havia evitat contestar públicament a Llombart. En aquesta ocasió ho fa amb un to més moderat:

En 1877, cedint á les repetides instancies de sos amichs y admiradors, baix lo modest títol de Rimas, reuní y publicá en un volúm en quart [...] ses inapreciables poesíes castellanes [...] y seguides, ab prou sentiment nostre, de sols tres composicions llemosines, que no sabem per quin fundat motiu lo poeta nomena catalanes (1879a: 397-398).

Més endavant, l'agost de 1881, l'entitat Lo Rat Penat debat l'aprovació dels seus primers estatuts i Llombart, junt amb Josep Maria Puig i Torralva,

REVISTA VALENCIANA DE FILOLOGIA / IV (2020) p. I65-I 88

ADRIÀ MARTÍ-BADIA

L'origen, la identitat i el nom de la llengua catalana segons Constantí Llombart / i 80 
es queda sol en la defensa dels noms «llemosí» $\mathrm{i}$ «llemosí-català» —respectivament— i finalment s'aprova "valencià» (Ferrando 2006: 214).

Altrament, en l'Ensayo de Ortografía lemosino-valenciana, citat adés, Llombart lamenta la manca de valencians que es dediquen «al estudio de nuestra materna lengua lemosina» i que hi haja qui la menyspree «calificándola desdeñosamente de algarabía» (1887a: Xv). Després, anima els valencians a estudiar i aprendre

cuantos idiomas quieran, [...] mas nunca olviden que en ninguno de ellos conseguirán, por más que se afanen, darles á sus pensamientos tan expresiva y adecuada forma, como en su propia lengua (1887a: XVI).

I ho argumenta de manera contundent:

Mas no es asunto baladí el cultivo de nuestra lengua; en ella está como encarnado el espíritu de un gran pueblo, y siendo un idioma el primero de los elementos que constituyen la existencia esencial y característica de cualquier país, es un deber principal, una sagrada obligación la que todos tenemos de mantener, conservar y perfeccionar el materno idioma, inapreciable herencia que nos legaron nuestros venerables antepasados (1887a: XVI).

També celebra que «la Sociedad de amadores de las glorias valencianas Lo Rat-Penat, ha levantado en Valencia su majestuoso vuelo el renacimiento de nuestra literatura lemosina» (1887a: XVI). I considera que la millor solució per a la llengua és

Establecer una doble división de lugar y tiempo en nuestra lengua [...]. La primera de ellas [...] la que al punto donde se habla se refiere, reducida está á la aplicación indistinta del calificativo lemosín á las tres diversas ramas del árbol de nuestra lengua, que son el catalán, el mallorquín y el valenciano, denominándose respectivamente lemosino-catalán, lemosino-mallorquín y lemosino-valenciano, según a la región á que

REVISTA VALENCIANA DE FILOLOGIA / iv (2020) p. I65-I88

ADRIÀ MARTÍ-BADIA

L'origen, la identitat i el nom de la llengua catalana segons Constantí Llombart / I8 I 
corresponda; y no omitiéndose nunca el dictado lemosín, ya que tal fué el nombre de pila que, por razón de haber nacido en Limoges, así como por haber nacido en Castilla se denomina la lengua española castellana, la es en todos casos apropiado. De este modo obtendrianse las consiguientes ventajas de facilitar en mucho la unificación de nuestra lengua, pudiendo, por otra parte, desarrollarse autonómicamente en cada una de por sí, evitándose quizás mezquinos recelos ó antagonismos que entre sus cultivadores pudieran algún día suscitarse.

Respecto á la división de tiempo, bueno fuera atenerse al pasado, al presente y aun al porvenir, y establecer tres diferentes géneros de lenguaje: uno correspondiente al pasado, ó sea el lemosín arcaico; otro al presente, que podría llamarse lemosín literario, y ha de ser el que con el actual renacimiento se forme; y por último, el dialecto valenciano, especie de caló, corruptela de nuestra antigua lengua valenciana, y que hoy ordinariamente usamos (1887a: XVII).

D’aquesta manera, els «recelos» esmentats són l'element que decanta la proposta onomàstica de Llombart qui, segons Rafanell (1991: 44), «pretén fer passar el que és una intuïció defensiva per una convicció plenament assumida». Finalment, el 1889 publica a la revista El Archivo l'article titulat «Notas biblio-biográficas. Un diccionario valenciano-castellano inédito», en què dona notícia de l'obra de Tomàs Font i Piris (1852) i en el qual torna a referir-se a la llengua catalana amb el mot «lemosín» (1889: 297b, 300a).

La seua posició respecte al nom del conjunt de la llengua catalana també l'explicita en les seues relacions epistolars, com s'hi observa en una carta que tramet el 15 d'abril de 1891 a l'hispanista alemany Johannes Fastenrath —qui havia traduït diverses poesies catalanes a l'alemany:

Permítame V. hacerle una observación. Bajo la denominación de trovadores catalanes nos comprende V. a valencianos y mallorquines, cuando ni ahora ni nunca la lengua y literatura de estos últimos fue llamada cata[la]na ni en las Islas Baleares ni en Valencia. En cambio, hasta no

REVISTA VALENCIANA DE FILOLOGIA / IV (2020) p. I65-I 88

ADRIÀ MARTÍ-BADIA

L'origen, la identitat i el nom de la llengua catalana segons Constantí Llombart / I 82 
hace muchos años, lo mismo catalanes que mallorquines y valencianos, ateniéndonos al común origen de nuestra lengua materna, indistintamente hemos apellidado siempre lemosín el catalán, mallorquín y valenciano. ¿Qué fin se proponen con esta modernísima innovación los escritores y poetas del Principado? Nunca he podido creer, como algunos suponen, que pretendían los catalanes, por este medio, absorver a valencianos y mallorquines; pero si esto fuera así, seguramente jamás habían de conseguirlo, ya que no tan fácilmente renuncia ningún pueblo a nada de lo que constituye su propia existencia. Por mi parte, siempre que del lenguaje valenciano se trata, denomínole lemosín o lemosino-valenciano. Así también lo han calificado y siguen calificando el suyo los mallorquines, y francamente, no hallo razón ni fundamento para que, rechazando este apelativo que siempre admitieron los catalanes, muestren ahora interés en comprendernos a todos con el nombre genérico de catalanes. Esto ni ha sido, como ya he dicho, ni tampoco será nunca. Téngalo V. en cuenta por si le conviene consignarlo. ${ }^{9}$

Amb aquesta lletra, Llombart evidencia que era coneixedor del que publicaven els estudiosos estrangers sobre la llengua catalana i —el que més el preocupava - amb quin nom s'hi referien, qüestió en què es mostrava inflexible.

En definitiva, Llombart no només va tractar de justificar filològicament l'ús del nom llemosí per al conjunt de la llengua catalana, sinó que es va mantindre inflexible en els seus escrits i va arribar a l'enfrontament dialèctic amb el valencià Vicent V. Querol i el català Antoni Careta i Vidal.

\section{L'origen de la llengua catalana}

Quasi tots els escriptors i erudits valencians coetanis de Llombart continuen en la posició llemosinista, segons la qual el conjunt de la llengua catalana

9 Citem el text de Roca (2016: 151-152), que el transcriu i regularitza la puntuació, l'accentuació, les majúscules i minúscules, l'apòstrof i el guionet.

REVISTA VALENCIANA DE FILOLOGIA / IV (2020) p. I65-I 88

ADRIÀ MARTÍ-BADIA

L'origen, la identitat i el nom de la llengua catalana segons Constantí Llombart / I 83 
tindria un origen comú amb l'occitana — que aleshores anomenen «llemosina»-. D'acord amb aquest raonament, en origen, el català i l'occità eren la mateixa llengua romànica, però ambdues es van separar i esdevingueren llengües independents. Una tesi que la filologia romànica del segle xIx ja havia superat, demostrant l'origen singular del conjunt de la llengua catalana, llatí però deslligat de l'occità des de l'inici.

Al llarg d'aquest treball hem vist exemples implícits de l'argumentació de Llombart sobre l'origen de la llengua catalana, però tot seguit en veiem dos ben explícits. El primer és el de l'esmentat discurs Excel-lencies de la llengua Llemosina de 1878, en el qual, segons Llombart, la «llengua llemosina»

Es parlá en Aix, en Marsella, en Tarasco, en Orange, en totes les principals ciutats de la Prohénça; en la Galia gótica ó Langüedoch y ses cultes ciutats de Montpeller y Tolosa, com aixís mateix en la provincia confinant de Guyena y en sa capital Burdeos, y molt especialment en Limoges, de la que'l nom vá pendre, y que hi va pertanyer á la Galia Narbonense. Fonch formada aquesta llengua, llavors, parlada en tantes provincies, de la espanyola, ó bé sia, romana vulgar ó romanç meçclada ab la goda dominant, qu'en ella introduhiren los que de la península de Espanya fugiren á França en la general invasió d'els moros, any [...] setcents dotce, meçclantla també ab la mixta francesa [...] y no hi manca tampoch algú que crega que vá penetrar fins París (1878b: 12-13).

A més, sosté que en la mateixa llengua fou criat a Montpeller «y parlá nostre molt alt é invicte Rey En Jaume», amb la qual va escriure «á imitació de Juli César, ses conquestes y á imitació d'els romans la introduhí ab la sua religió en les Mallorques, y en Valencia y son antich regne al conquestarlos». I, amb les conquestes posteriors, «de Valencia, Aragó y Catalunya [...] s’introduhí lo llemosí en los regnes de Cerdenya, Nápols y Sicilia» (1878b: 13). Seguint la seua argumentació

La llemosina llengua fonch la cortesana ab qu'en Aragó, Valencia y Catalunya, los reys parlaben, y ab la qu'En Pere Iv, lo Cerimoniós, com-

REVISTA VALENCIANA DE FILOLOGIA / IV (2020) p. I65-I 88

ADRIÀ MARTÍ-BADIA

L'origen, la identitat $i$ el nom de la llengua catalana segons Constantí Llombart / I 84 
pongué sa real historia; disentint aquesta llengua en los tres amunt citats domini, sols en alguna qu'altra petita variació, ya que en la manera de pronunciarse, ya en la adopció d'algunes veus originaries, insignificants, diferencies molt menys notables si es vol encara, que les que'l castellá sofrix en les diverses provincies hon se parla $(1878 b$ : 15$)$.

Un discurs en què Llombart gairebé no explota la gran quantitat de noms il-lustres que podrien donar crèdit a la seua proposta (Rafanell 1991: 42). En aquest sentit, cita Martí de Viciana, però dedica la major part del seu parlament a plagiar el pròleg d'Agustí Sales al Diccionario de Carles Ros (1764).

L'altre exemple és de 1887, en el següent fragment de Valencia antigua y moderna, on afirma:

La lengua provenzal ó prohenzal, nacida en la parte del Mediodía de Francia, y popularizada en el principado de Cataluña, adquirió más regularidad, más armonía y mayor número de voces, haciendo desaparecer casi del todo la que con tanta celebridad se hablaba allende los Pirineos, y ofreciendo por consiguiente tanta variacion, que llegó á formar casi una lengua diferente, distinguiéndose en lemosina y provenzal (1887b: 63).

\section{Conclusió}

Llombart és un dels valencians que més es va interessar pel nom i la identitat de la llengua dels valencians, com demostren, d'una banda, les nombroses vegades que va escriure sobre ambdós temes i, de l'altra, pel fet d'impulsar la creació de l'Acadèmia «Los fills de la mórta viva» (1875) i l'«Academia Ausias-marchina» (1885) per al treball en favor de la codificació i l'estudi de la llengua catalana.

Tot amb tot, pel que fa a la identitat de la llengua reconeix el valencià com a part de la llengua catalana, com ho van fer la pràctica totalitat d'escriptors i erudits de la seua època. Quant al nom amb què calia referir-s'hi, Llombart es va mostrar implacable a l'hora d'anomenar «llemosina» la llengua

REVISTA VALENCIANA DE FILOLOGIA / IV (2020) p. I65-I 88

ADRIÀ MARTÍ-BADIA

L'origen, la identitat $i$ el nom de la llengua catalana segons Constantí Llombart / I 85 
catalana com a estratègia per a evitar la denominació unitària «català» - i derivats-perquè no satisfà les seues aspiracions identitàries, i va arribar a l'enfrontament dialèctic amb el valencià Vicent W. Querol i el català Antoni Careta i Vidal. A més, a diferència d'altres escriptors coetanis, va intentar justificar filològicament l'ús d'aquest nom, perquè — segons ell- valenciana, catalana i balear eren tres branques de la llengua occitana — que aleshores anomenen «llemosina»-, nascuda a Llemotges. Així doncs, d'acord amb aquest raonament, en els seus orígens, el català i l'occità haurien estat la mateixa llengua romànica, però, amb el temps, ambdues es van separar i esdevingueren llengües totalment independents. Aquesta tesi, la filologia romànica del segle xix ja l'havia superada, demostrant l'origen singular del conjunt de la llengua catalana, llatí, en efecte, però deslligat de l'occità des de l'inici.

\section{Bibliografia}

Anònim (1887) «Novas», L’Arch de Sant Martí, 309, pp. 947-952.

Balaguer, V. (1876) Tragèdies, Barcelona, La Renaixensa.

Bernat i Baltrons, F. (2017) «La crisi del llemosinisme a la Catalunya del vuit-cents», dins A. Carrera i I. Grifoll (eds.), Occitània en Catalonha: de tempses novèls, de novèlas perspectivas. Actes de l'Ixen Congrès de l'Associacion Internacionala d'Estudis Occitans, Barcelona / Lleida, Departament de Cultura de la Generalitat de Catalunya / Diputació de Lleida / Institut d'Estudis Ilerdencs, pp. 315-325.

Borx, V. (1845) Historia de la ciudad y reino de Valencia, vol. I, València, Benito Monfort. Careta i Vidal, A. (1875) «Bons recorts», Calendari Catalá del any 1876, pp. 9-13.

Climent, J. D. (2003) L'interés per la llengua dels valencians (segles XV-XIX), València, Consell Valencià de Cultura.

Estrela, J. E. (2018) Esperit de valencianisme. Constantí Llombart (1848-1893), València, Institució Alfons el Magnànim.

Fenollar, B. (et al.) (1877 [1a ed. 1497]) Lo procés de les olives, C. Llombart (ed.), València, Francesc Aguilar.

Ferrando, A. (2006) «Percepció i institucionalització de la norma lingüística entre els valencians: panorama històric (1238-1976)», dins A. Ferrando i M. Nicolás (eds.), La configuració social de la norma lingüística a l'Europa llatina, Alacant, IIFV, pp. 189-251.

REVISTA VALENCIANA DE FILOLOGIA / IV (2020) p. I65-I 88

ADRIÀ MARTÍ-BADIA

L'origen, la identitat $i$ el nom de la llengua catalana segons Constantí Llombart / I 86 
Font i Piris, T. (1852) Diccionario valenciano-castellano, Cullera, inèdit.

Fuster, J. (1962) Qüestió de noms, Barcelona, Aportació Catalana.

Guardiola i Savall, M. I. (2005) «L'aportació de Llombart al diccionari d'Escrig» dins V. J. Escartí i R. Roca (eds.), Constantí Llombart i el seu temps, València, Acadèmia Valenciana de la Llengua, pp. 233-255.

Llombart, C. (1874) «Tot vól escomensar», Lo Rat-Penat. Calendari Llemosí corresponent al present any 1875 , pp. 9-16.

- (1875), «Revista de l'any passat», Lo Rat-Penat. Calendari Llemosí corresponent al present any 1876, pp. 11-18.

— (1876a [1a ed. 1872]), Niu d'abelles. Epigrames llemosins, València, Pasqual Aguilar, 2a ed.

- (1876b), «Revista de l'any passat», Lo Rat-Penat. Calendari Llemosí corresponent al present any 1877, pp. 11-16.

- (1877), «Revista de l'any passat», Lo Rat-Penat. Calendari Llemosí corresponent al present any 1878, pp. 11-16.

- (1878a), Abelles y abellerols. Sent y un epígrames, València, Emilio Pascual.

- (1878b), Excel-lencies de la llengua Llemosina. Discurs panegirich llegit en la solemne sesió inaugurativa de Lo Rat-Penat, València, Emili Pasqual.

— (1878c), «Revista de l'any passat», Lo Rat-Penat. Calendari Llemosí corresponent al present any 1879, pp. 11-16.

- (1879a), Los fills de la morta-viva. Apunts bio-bibliográfichs per a la historia del renaiximent lliterari llemosí, València, Emili Pasqual.

- (1879b), «Revista de l'any passat», Lo Rat-Penat. Calendari Llemosí corresponent al present any 1880, pp. 11-16.

- (1887a [1a ed. 1851]), Diccionario valenciano-castellano de José Escrig, vol. I, València, Pascual Aguilar, 3 a ed.

- (1887b), Valencia antigua y moderna, València, Pascual Aguilar.

— (1889), «Notas biblio-biográficas. Un diccionario valenciano-castellano inédito», El Archivo, tom III, pp. 296b-302a.

Marcet, P. (1991[1a ed. 1987]) Història de la llengua catalana, vol. II, Barcelona, Teide, 2a ed.

Martí-Badia, A. (2013) «La ideologia lingüística de Marc Antoni d'Orellana», eHumanista/ IVITRA, 3, pp. 272-287, disponible en línia a https://www.ehumanista.ucsb.edu/ sites/secure.lsit.ucsb.edu.span.d7_eh/files/sitefiles/ivitra/volume3/12_marti_badia.pdf [Consulta: 3-1-2020].

- (2019) «Els postulats de la filologia romànica internacional sobre l'origen, la identitat i el nom de la llengua catalana (1806-1906)», Scripta, 13, pp. 60-80, disponible en línia a <https://ojs.uv.es/index.php/scripta/article/view/15436/14112> [Consulta: 7-2-2020].

Martí Mestre, J. (2005) «Constantí Llombart i la llengua» dins V. J. Escartí i R. Roca (eds.), Constantí Llombart i el seu temps, València, Acadèmia Valenciana de la Llengua, pp. 201-231.

REVISTA VALENCIANA DE FILOLOGIA / IV (2020) p. I65-I88

ADRIÀ MARTÍ-BADIA

L'origen, la identitat i el nom de la llengua catalana segons Constantí Llombart / I 87 
Mulet, F. (1876) Obres festives, C. Llombart (ed.), València, Francesc Aguilar, 2a ed.

PItarch, V. (1972) Defensa de l'idioma, València, Tres i Quatre.

Querol, V. W. (1877) Rimas, València, J. Doménech.

RAFAnell, A. (1991) «El llemosinisme valencià a la darreria del segle XIX», Caplletra, 11, pp. 35-50.

RocA, R. (2016) «Els discursos sobre la llengua literària en la Renaixença valenciana» dins

F. Feliu i J. M. Nadal (eds.), Constructing Languages. Norms, myths and emotions, Amsterdam, John Benjamins Publishing Company, pp. 145-161.

Ros, C. (1764) Diccionario valenciano-castellano, València, Benito Monfort.

Tubino, F. M. (1880) Historia del Renacimiento literario contemporáneo en Cataluña, Baleares y Valencia, Madrid, M. Tello.

Verdaguer, J. (1981) Epistolari de Jacint Verdaguer, vol. vi, Barcelona, Barcino.

REVISTA VALENCIANA DE FILOLOGIA / IV (2020) p. I65-I 88

ADRIÀ MARTÍ-BADIA

L'origen, la identitat $i$ el nom de la llengua catalana segons Constantí Llombart / I 88 